\title{
La enseñanza de la lectura y la mediación cognitiva en estudiantes de media académica: Estudio de correlación
}

\author{
The Teaching of Reading and Cognitive Mediation in Students of Academic Average: A \\ Correlation Study
}

O ensino da leitura e da mediação cognitiva a estudantes de ensino médio: um estudo de correlação

\author{
Alba Luz Arenas-Parada \\ Instituto Universitario Veracruzano \\ Aguazul, Colombia \\ albaluzarenas@26hotmail.com \\ iD https://orcid.org/0000-0002-8527-9164 \\ Libardo Roa-Muños \\ Fundación Universitaria Internacional del Trópico Americano Unitrópico \\ Yopal, Colombia \\ libardoroa@unitropico.edu.co \\ iD https://orcid.org/0000-0001-6749-1180 \\ Jairo Abelardo Centeno-Villamizar \\ Fundación Universitaria Internacional del Trópico Americano Unitrópico \\ Aguazul, Colombia \\ jairo0502@gmail.com \\ (iD) https://orcid.org/0000-0001-5884-4562 \\ Kenier Iván Téllez López \\ Fundación Universitaria Internacional del Trópico Americano Unitrópico \\ Yopal, Colombia \\ ivantellez@unitropico.edu.co \\ https://orcid.org/0000-0001-9680-4799
}

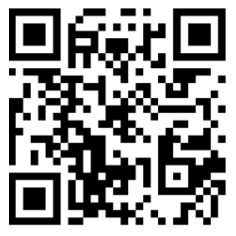

Recibido • Received • Recebido: $06 / 12$ / 2019

Corregido • Revised • Revisado: 25 / 07 / 2021

Aceptado • Accepted • Aprovado: 25 / 08 / 2021

\begin{abstract}
Resumen
Objetivo. Este artículo científico de investigación tiene por objetivo determinar la relación que existe entre el proceso de lectura con apoyo de las TIC y la mediación cognitiva de estudiantes de educación media. La mediación cognitiva a la que se expone el estudiantado en su desarrollo escolar involucra una serie de factores como la intencionalidad, la trascendencia y el sentimiento de competencia que pueden analizarse en función de la actividad lectora. Metodología. Esta investigación de enfoque cuantitativo estableció la correlación entre el proceso de lectura con apoyo de las TIC y la mediación cognitiva; se tomó una muestra estratificada con estudiantes de grados décimo y undécimo de una
\end{abstract}


http://doi.org/10.15359/ree.25-3.36

http://www.una.ac.cr/educare

educare@una.ac.cr

institución educativa pública. Los datos se obtuvieron a partir de la aplicación de la técnica tipo encuesta; desarrollada en un instrumento en formato cuestionario con escala Likert y se sometieron a revisión de juicio experto, más prueba de normalidad, en SPSS, determinando coeficiente de Pearson. Resultados. Los datos estadísticos, revelaron dificultades en la fluidez y en el sentimiento de competencia de la mediación cognitiva. Conclusiones. Es posible afirmar que existe correlación baja positiva entre el proceso de lectura con apoyo de las TIC y la intencionalidad, la trascendencia y el sentimiento de competencia.

Palabras claves: Fluidez lectora; lectura, mediación cognitiva; tecnología de la información y la comunicación (TIC).

\begin{abstract}
Objective. This scientific research article aims to determine the relationship between the ICTsupported reading process and the cognitive mediation of high school students. The cognitive mediation to which a student is exposed in their school development involves a series of factors such as intentionality, significance, and the feeling of competence that can be analyzed based on reading activity. Methodology. This research with a quantitative approach established the correlation between the ICT-supported reading process and cognitive mediation. A stratified sample with tenth- and eleventh-grade students from a public school was selected. The data were obtained from the application of a survey-type technique, developed in a questionnaire format instrument with a Likert scale. The data were submitted to an expert review, plus normality test, in SPSS, determining Pearson's coefficient. Results. Statistical data revealed difficulties in fluency and the feeling of competence of cognitive mediation. Conclusions. It is possible to affirm that there is a low positive correlation between the ICT-supported reading process and intentionality, significance, and the feeling of competence.
\end{abstract}

Keywords: Reading fluency; reading; cognitive mediation; Information and Communication Technology (ICT).

\title{
Resumo:
}

Objetivo. Este artigo de pesquisa científica tem como objetivo determinar a relação entre o processo de leitura apoiado pelas TIC e a mediação cognitiva de estudantes do ensino médio. A mediação cognitiva a que são expostos o grupo de estudantes no seu desenvolvimento educativo envolve uma série de fatores como a intencionalidade, a significância e o sentimento de competência que podem ser analisados a partir da atividade de leitura. Metodologia. Esta pesquisa com abordagem quantitativa estabeleceu a correlação entre o processo de leitura suportado pelas TIC e a mediação cognitiva; foi usada uma amostra estratificada com estudantes do décimo e décimo primeiro ano de uma instituição pública de ensino. Os dados foram obtidos a partir da aplicação da técnica do tipo questionário; desenvolvido num instrumento em formato de perguntas com escala Likert e foram submetidos à revisão de especialistas, além de teste de normalidade, no SPSS, determinando o coeficiente de Pearson. Resultados. Os dados estatísticos revelaram dificuldades na fluência e no sentimento de competência da mediação cognitiva. Conclusões. É possível afirmar que existe uma baixa correlação positiva entre o processo de leitura apoiado pelas TIC e a intencionalidade, transcendência e sentimento de competência.

Palavras-chave: Fluência de leitura; leitura; mediação cognitiva; tecnologia da informação e comunicação (TIC). 


\section{Introducción}

La lectura como tema de investigación se ha desarrollado principalmente en los procesos de comprensión de textos. Ahora bien, en el proceso de leer, la fluidez constituye un capítulo que cobra cada vez más importancia (Rasinski, 2004). Según Fumagalli et al. (2017), la fluidez está significativamente relacionada con la comprensión de textos.

Durante el proceso de observación directa se pudo evidenciar que, la fluidez lectora en algún estudiantado del nivel de educación media de una institución educativa pública no ha sido desarrollada de manera eficiente; incluso, en casos excepcionales, es comparable con la fluidez alcanzada por estudiantes regulares de nivel de educación básica primaria. A raíz de esto, vale la pena cuestionarse acerca de la incidencia de estrategias que favorezcan el proceso lector; el estudiantado es el eje central del aprendizaje significativo y en ese sentido, el constructivismo en consonancia con el conectivismo se integra para proveer nuevas formas de leer en el proceso de enseñanza aprendizaje (Piaget, 1985; Siemens, 2004; Vygotsky, 1978).

El nivel de competencia de lectura no solo está determinado por la capacidad de comprensión del texto; sino también, por su fluidez a la hora de leer. Una de las dificultades que se evidencian en el sistema educativo nacional, en los niveles básicos y secundarios, está delineada por la falta de fluidez; capacidad que puede enmarcarse en algunos procesos concretos, tales como el silabeo, la repetición innecesaria de palabras, sustitución o adición de acepciones que hacen parte o no del texto (de Zubiría Samper, 1996; Sánchez 1990). La preocupación por analizar la fluidez lectora ha inquietado a personas investigadoras; en Argentina, por ejemplo, el trabajo de Fumagalli et al. (2017) destaca la relevancia del problema, en este caso particular, por su incidencia en la comprensión de textos. En España, Gutiérrez (2018) analizó habilidades que favorecen el aprendizaje de la lectura en niñez de 5 y 6 años.

Para Funes (1995), existe un enfoque psicolingüístico-cognitivo rastreable en las dificultades de lectura. Lo expuesto abre paso al mapa cognitivo que presenta Pilonieta (2010) en sustento del estudio realizado por Feuerstein et al. (1991) sobre la modificabilidad cognitiva, aplicable a deficiencias en lectura propuestas en trabajos separados por de Zubiría Samper (1996) y Sánchez (1990).

Esta investigación es de enfoque cuantitativo, correlacional con diseño no experimental, cuyo propósito es determinar la relación que existe entre el proceso de lectura con apoyo de las TIC y la mediación cognitiva de estudiantes de media de una I. E. pública. El aporte práctico está demarcado por el desarrollo cognitivo en el proceso de aprendizaje del estudiantado, especialmente por tratarse de un trabajo de lectura. Las actividades mediadas por TIC son, en esencia, una forma de mostrar la lectura al estudiantado en un panorama distinto al tradicional con aporte significativo a su mediación cognitiva. 
http://doi.org/10.15359/ree.25-3.36

http://www.una.ac.cr/educare

educare@una.ac.cr

Dentro de los antecedentes se halló que, en el contexto educativo, las TIC se están implementando incluso para el desarrollo de habilidades de lectura crítica asociada a la cognición y dentro de ellas, la motivación, la capacidad para comparar o asumir posturas que mueven al estudiantado a contrastar el texto en papel con la versatilidad del texto en pantalla (Silva Manrique et al., 2019). En la relación entre lectura y TIC se han analizado variables alternas como el rendimiento académico o el desempeño en pruebas estatales de donde derivan factores que pueden considerarse, como la edad, el nivel socioeconómico, la intensidad horaria y el acceso a las herramientas tecnológicas (Timarán Pereira et al., 2020).

En cuanto a la lectura y su relación con la mediación cognitiva, Gómez Martínez (2007) establece un análisis desde la perspectiva de docentes y la enseñanza de la comprensión lectora resaltando como funciones cognitivas: la comprensión superficial del texto al leer fluidamente y mantener una conducta planificada y sistemática; la comprensión del significado básico del texto al comparar objetos, dominar fuentes de información y atender significados del texto; y la comprensión con inferencias al relacionar ideas, deducir nueva información, plantear problemas y construir correctamente el texto. Según Gómez Martínez (2007), cada una de estas acciones sobre el texto requieren de una operación mental y de su correspondiente mediación.

\section{Marco teórico}

El abordaje teórico se estructura en dos secciones; por un lado, se analiza la lectura como proceso; por el otro, el análisis de la mediación cognitiva. En los dos casos, se mantiene la idea que la lectura implica una transformación cognitiva en el estudiantado (Amórtegui Luna, 2017).

\section{La lectura como proceso}

De la teoría de las seis lecturas, de Zubiría Samper (1996), se prestó especial interés en los primeros cuatro niveles: La lectura fonética, en la que el estudiantado (sujeto lector) alcanza un análisis y síntesis de palabras a través del establecimiento de la relación entre logra determinar el significado exacto de las palabras que ofrece el texto. Seguido a este, deviene la decodificación secundaria, donde la persona lectora es capaz de hallar proposiciones derivadas de las oraciones. Un cuarto nivel, denominado por el autor, decodificación terciaria, consiste en la identificación de macroproposiciones; el sujeto lector logra entender relaciones lógicas, temporales, espaciales de las ideas que se han diseminado en el texto.

Sánchez (1990) establece que uno de los problemas de la lectura consiste en la segmentación, de modo similar lo plantea de Zubiría Samper (1996) a través de la lectura fonética; el sujeto lector pone en funcionamiento la relación de los sonidos con los fonemas y grafemas; describe el problema en la conversión de símbolos en sonidos cuando lee en voz alta, por un asunto de comprensión en la representación de ellos. Otro problema es la percepción, que debe 
http://doi.org/10.15359/ree.25-3.36

analizarse desde dificultades que se registran en torno a la orientación en el espacio, en el tiempo, dificultades de estructuras rítmicas o en el discernimiento de formas (Sánchez, 1990).

En el texto Estrategias de intervención en los problemas de lectura, Sánchez (1990) plantea interrogantes acerca del procedimiento empleado para enseñar a leer y la forma de abordar problemas de alumnado que lee con dificultad.

Proceso de lectura con apoyo de las TIC. Hace varias décadas que el aprendizaje de la lectura se desarrolla con apoyo de herramientas informáticas (Hurtado, 2010). La tecnología se ha insertado con éxito en el proceso de lectura de estudiantes, donde el personal docente juega un papel fundamental (Paredes Labra, 2005). También, las TIC influyen decisivamente en la habilidad de comprensión de textos que deben trabajar estudiantes, al generar motivación hacia el desarrollo de las actividades, lo que incentiva a corregir los malos hábitos de lectura, tal como lo plantean Carmona García y Martínez Gutiérrez (2012).

De igual forma, Tabash Blanco (2010) asegura que la lectura interactiva contribuye de manera significativa en resolver problemáticas de enseñanza tradicional, promueve la calidad del aprendizaje y el desarrollo de competencias lingüísticas.

Por otra parte, la lectura se complementa a través de las TIC, puesto que las herramientas tecnológicas actuales ofrecen alternativas que se ajustan a la ausencia de sentidos; por ejemplo, una lectura sonora, donde el programa lee el texto a una persona que carece de visión; sistemas de reconocimiento de voz, que ayudan a las personas a navegar y encontrar rápidamente la lectura que necesitan (Guenaga et al., 2007).

\section{Dimensiones de la variable proceso de lectura}

La segmentación o silabeo. Cuando se lee un texto, la conciencia fonológica no habituada obliga a segmentar las palabras en sílabas ralentizando la lectura; en algunas investigaciones, la sílaba se ha analizado desde una corriente estructural, o desde una postura tradicional; aun así, coinciden en que la sílaba es de orden fonético (Fraca de Barrera, 1998). Sin embargo, para Fraca de Barrera (1998), el peldaño fundamental para la enseñanza-aprendizaje de la lengua, tanto escrita como de lectura, requiere de un buen desarrollo cognitivo en el silabeo. En otras investigaciones, se ha abordado esa conciencia fonológica como la codificación fonológica desde las funciones cerebrales que entran en acción para las representaciones fonémicas y grafémicas permitiendo así que el cerebro se reorganice desde los cambios conductuales que diferencian a los sujetos analfabetos de los alfabetizados (Dehaene et al., 2015). Si se presentan fallas en el adecuado desarrollo de la codificación fonológica, serán visibles aparentes trastornos en los procesos de lectura; por ello, debe recibir especial atención esta etapa de lectura por ser inicial y por ser base de todos los niveles subsiguientes. Estudios de Dehaene (2014) se enfocan en las conexiones neuronales activadas a través de la lectura a lo que llama cerebro lector. 
http://doi.org/10.15359/ree.25-3.36

http://www.una.ac.cr/educare

educare@una.ac.cr

La percepción o decodificación. Existe un comportamiento evolutivo del aprendizaje de la lectura, especialmente en el tema de la decodificación, en donde se analiza un procesamiento subléxico por parte del sujeto lector, esto implica fijación en algunas características descubiertas del sistema: linealidad y correspondencia fonográfica (Vaca Uribe, 2000). Adicionalmente, no basta con realizar una percepción visual, sino que es necesario hacer un acto perceptivo. De acuerdo con Filinich (2003), el acto perceptivo es de un nivel superior a la percepción visual; mientras que Parret (1995) refiere la percepción olfativa, táctil y auditiva como complemento de la percepción visual usada en la lectura.

Defectos al leer. Algunos defectos al leer se identifican realizando un ejercicio de seguimiento de la lectura, dondeel estudiantadovaleyendoysu docentelo sigue detalladamente, resaltando el momento en que cada estudiante no lee adecuadamente una palabra, bien sea por omitir o agregar letras, o por sustituirlas. Si esta es la raíz de algunos problemas de lectura, cabe razonar la necesidad de "proporcionar a los alumnos experiencias y tareas que faciliten esa toma de conciencia sobre la estructura fónica de las palabras" (Sánchez, 1990, p. 140).

\section{La mediación cognitiva}

Inciarte Romero e Inciarte González (2014) estiman la mediación cognitiva como una tecnología social de elevado potencial educativo; resaltan características de flexibilidad y de allí la posibilidad de transformar dificultades en experiencias de aprendizaje. En la mediación cognitiva, la planificación que realiza el personal docente es fundamental para que el estudiantado desarrolle aprendizajes significativos; de manera específica, la planeación debe estar ligada a una serie de tareas progresivas que el estudiantado debe ir desarrollando poco a poco para que pueda emprender tareas de mayor complejidad (Núñez París, 2010).

La mediación cognitiva expuesta por Pilonieta (2010), y sustentada también en los trabajos de Feuerstein, propone que "la mejor forma de desarrollar conocimiento significativo es fusionar los conceptos con los procedimientos y sus aplicaciones ... base de la adquisición de conocimiento teórico" (p. 182). En ese sentido, una mediación crítica, literaria, soportada en una pedagogía crítica, requiere de una reflexión del personal docente hacia una resignificación de conceptos, de conocimientos y de habilidades cognitivas (Fuentes Paipilla y Ramírez Sánchez, 2017). Por otra parte, aprender a leer, o mejorar el proceso lector en sí, estimula cambios neuronales y, por esta razón, incitan la comprensión del cómo enseñar, investigar y la comprensión de la producción de lenguajes (Luján Villar, 2015). También, como necesidad de relación entre la mediación cognitiva con la lectura, es necesario analizar que el estudiantado

que se encuentra en la etapa de elaboración de esquemas cognitivos asimila a través del discurso literario el conocimiento del medio que lo rodea, donde puede 
conformarse desde los códigos que este medio le proporciona. De este modo, fundamenta las estructuras mentales que serán la base de desarrollos posteriores en la delimitación de aprendizajes durante el transcurso de su ciclo vital. El proceso dialógico que establece el niño-lector con el texto literario otorga posibilidades de cognición situada, en donde los procesos son considerados en términos de relaciones entre individuos en una situación físico-social, y no como actividades que ocurren solo en la mente, [por tanto], la base de este desarrollo se concentra en la resolución de problemas en el accionar cotidiano que da sustento al desarrollo de la formación identitaria (Guiñez Elorz y Martínez Palma, 2015, p. 132).

La mediación cognitiva como teoría expone experiencias de aprendizaje mediado, la etiología proximal para el desarrollo diferencial de funciones cognitivas (Feuerstein y Rand, 1974). En una de esas experiencias, Feuerstein y colaboradores están de acuerdo en que existen condiciones ambientales que influyen de manera significativa en el desarrollo cognitivo; ante esto, plantean el aprendizaje mediado como alternativa que prepara el trabajo del desarrollo cognitivo.

Fundamentos específicos sobre mediación cognitiva. En la mediación cognitiva, la planeación debe estar ligada a una serie de tareas progresivas que el estudiantado debe ir desarrollando paulatinamente y pueda emprender tareas de mayor complejidad (Núñez París, 2010). En relación con la lectura, la mediación cognitiva, "para que un texto cobre vida necesita de motivación, de curiosidad, de dedicación, de tiempo y de alguien que promueva esto, de alguien que transmita ese gusto por leer" (Guiñez Elorz y Martínez Palma, 2015, p. 118).

\section{Fundamentos de las dimensiones de la variable mediación cognitiva}

Intencionalidad. La intencionalidad implica una serie de acciones, por tratarse de la primera reacción del estudiantado. El punto de partida tiene que ver con el propósito de las actividades que se postulan para trabajar en clase (Guiñez Elorz y Martínez Palma, 2015). Tebar Belmonte (2009) sugiere parámetros significativos para entender la intencionalidad desde un enfoque de reciprocidad; dentro de ellos, señala que el sujeto debe mostrarse empático y confiado de manera que pueda enfocarse en la consecución de objetivos definidos. Agrega Tebar Belmonte (2009) que en el sujeto lector se debe notar expresividad en su rostro, modulación de su voz y contacto visual; en todo esto, la persona mediadora debe mantenerse alerta para generar los estímulos necesarios que le permitan administrar un ambiente propicio para el desarrollo de la intencionalidad.

Trascendencia. Se relaciona con la importancia que el estudiantado le atribuye al aprendizaje, también al valor que le da al tiempo (Guiñez Elorz y Martínez Palma, 2015). Cuando 
http://doi.org/10.15359/ree.25-3.36

http://www.una.ac.cr/educare

educare@una.ac.cr

entiende el uso de sus aprendizajes escolares en contextos futuros, se produce la sensación de trascendencia "y la aplicación de los aprendizajes a otros saberes de la vida" (Tébar Belmonte, 2009, p. 165).

Sentimiento de competencia. Se enfoca en la actitud que el estudiantado asume frente a la motivación en torno al aprendizaje (Guiñez Elorz y Martínez Palma, 2015). Más allá de la motivación, "progresivamente el niño va identificando las cosas bien o mal hechas. Sus juegos de comprensión le van dando pautas de juicio sobre sus acciones"(Tébar Belmonte, 2009, p.168).

\section{Metodología}

Esta investigación de enfoque cuantitativo estableció la correlación entre el proceso de lectura con apoyo de las TIC (variable independiente) con la intencionalidad, la trascendencia y el sentimiento de competencia de la mediación cognitiva (variable dependiente). De esta manera, la lectura entendida como proceso requiere de la observación por parte del ente investigador, quien recoge la información que debe analizarse desde otra perspectiva. Al abordar las dos variables, ofrecen una visión más precisa de las acciones que deben seguirse.

\section{Diseño}

El diseño es no experimental, puesto que un factor fundamental de trabajo es la observación de una muestra de estudiantes en torno a la lectura, para conocer sus formas de leer y las dificultades que tienen después de haber concluido la mayoría de los ciclos de formación primaria y secundaria. En este sentido, y teniendo en cuenta los planteamientos de Hernández Sampieri et al. (2014), la investigación no establece las causas que ha llevado al estudiantado a leer con ciertas dificultades, ni el contexto en el que estas se han agravado o mejorado, esta es una investigación empírica donde las variables no son manipuladas, observando su relación en un contexto natural.

\section{Participantes}

La población corresponde a cuatro grupos de estudiantes de grados décimo y cuatro grupos de grado undécimo del Colegio Jorge Eliécer Gaitán, como se observa en la Tabla 1, es decir; 275 estudiantes en total al comenzar el año escolar 2018.

La muestra es estratificada con afijación proporcional; el margen de error en su máximo admitido fue de $5 \%$, de tal manera que se estableció un nivel de confianza de $95 \%$, con lo cual se obtuvo una muestra de 161 estudiantes. 
Tabla 1: Especificación de la muestra

\begin{tabular}{lccc}
\hline \multicolumn{1}{r}{ Grado } & N $^{\circ}$ sujetos & Proporción & Muestra del estrato \\
\hline Décimo A & 36 & $13,1 \%$ & 21 \\
Décimo B & 37 & $13,5 \%$ & 22 \\
Décimo C & 37 & $13,5 \%$ & 22 \\
Décimo D & 37 & $13,5 \%$ & 22 \\
Undécimo A & 32 & $11,6 \%$ & 19 \\
Undécimo B & 30 & $10,9 \%$ & 18 \\
Undécimo C & 34 & $12,4 \%$ & 20 \\
Undécimo D & 32 & $11,6 \%$ & 19 \\
\hline \multicolumn{1}{c}{ Total } & $\mathbf{2 7 5}$ & $100 \%$ & 161 \\
\hline
\end{tabular}

Nota: Elaboración propia a partir de la información de las personas participantes.

\section{Técnicas e instrumentos de recolección de datos}

Los datos se obtienen a partir de la aplicación de la técnica tipo encuesta; desarrollada en un instrumento en formato cuestionario con escala Likert de cuatro posibilidades 1 (nunca), 2 (a veces), 3 (casi siempre), 4 (siempre). La conveniencia de usar esta técnica radica en la versatilidad en su uso, en el tratamiento que se le puede dar a los datos y en la confiabilidad, pues aleja indicios de ambigüedad; las encuestas tipo Likert brindan "mayor cercanía de las respuestas al objetivo de la investigación, permiten recabar más información en menos tiempo, etc." (Cañadas Osinski y Sánchez Bruno, 1998, p. 623). Se estructuraron las preguntas en torno a las dos variables (variable 1, proceso de lectura; variable 2 , mediación cognitiva). De cada variable, se construyeron preguntas alrededor de las dimensiones y variables, con afirmaciones que indagan en el estudiantado su estado en relación con la variable y dimensión (ver Apéndice A).

De cada variable, se formularon 3 dimensiones; como lo muestra la Tabla 2. Para la variable proceso de lectura se tienen las dimensiones de segmentación-silabeo; las de percepcióndecodificación y defectos al leer; de estas dimensiones se construyeron 25 afirmaciones distribuidas; y medir la variable mediación cognitiva 3 dimensiones según el tipo de mediación: intencionalidad, trascendencia y sentimiento de competencia; de estas se construyeron 25 afirmaciones para (ver Apéndice B). 
http://doi.org/10.15359/ree.25-3.36

http://www.una.ac.cr/educare

educare@una.ac.cr

Tabla 2: Operacionalización de variables

\begin{tabular}{ll}
\hline \multicolumn{1}{c}{ Variables } & \multicolumn{1}{c}{ Dimensiones } \\
\hline \multirow{2}{*}{ Variable 1: proceso de lectura } & $\begin{array}{l}\text { Segmentación - Silabeo } \\
\text { Percepción - Decodificación } \\
\text { Defectos }\end{array}$ \\
\hline Variable 2: mediación cognitiva & $\begin{array}{l}\text { Mediación a partir de la intencionalidad } \\
\text { Mediación de la trascendencia } \\
\text { Mediación del sentimiento de competencia }\end{array}$ \\
\hline
\end{tabular}

Nota: Elaboración propia.

Por otra parte, el cuestionario se sometió a dos procesos de calibración. El primero de ellos, mediante la validación de personas expertas quienes determinaron en cada ítem su operatividad; a raíz de cada una de esas observaciones, se ajustó el instrumento (ver Apéndice B). En segundo lugar, se construyó el segundo proceso de calibración, fue el análisis de cada ítem por alfa de Cronbach usando la plataforma SPSS 20.0.

De acuerdo con esta información, la prueba piloto se aplicó a 10 estudiantes de otra institución con un contexto similar, contestaron el total de las 54 preguntas seleccionando el valor adecuado según sus propias experiencias.

Tabla 3: Datos estadísticos de fiabilidad

\begin{tabular}{ll}
\hline Alfa de Cronbach & $\mathrm{N}$ de elementos \\
\hline 0.837 & 54 \\
\hline
\end{tabular}

Nota: Elaboración propia.

Según la Tabla 3, el Alfa de Cronbach general para los 54 ítems planteados es superior a 0,8 con lo que se determinó un estadístico de fiabilidad positivo. Al revisar cada uno de los ítems, ninguno de ellos está por debajo de 0,8 tampoco ninguno llega o supera a 0,9. Como resultado del ejercicio de validación, la encuesta pasó de 54 afirmaciones a 50. Algunas preguntas se modificaron y mejoraron de acuerdo con las apreciaciones que arrojó el ejercicio de validación.

Sobre la lectura apoyada en las TIC, las actividades que se desarrollaron sirvieron para la observación del estudiantado y el análisis posterior a través del instrumento-cuestionario que resolvieron. En una de las actividades programadas en el ordenador, el estudiantado se enfrenta a la necesidad de leer en un tiempo límite una serie de palabras; las palabras son individuales y no tienen relación una con otra; la palabra aparece en pantalla por un lapso programado y al desaparecer, le abre paso a la siguiente palabra; se trabajaron grupos de 20 palabras; la dificultad avanzó programando de a dos palabras conectadas entre sí que desaparecían dando paso a otro conjunto de dos palabras hasta conseguir series de 20 palabras. Posteriormente, se aumentó la dificultad con 3 y más palabras bajo la premisa que a mayor cantidad de palabras, mayor la dificultad al leerlas "exigiendo" al estudiantado retarse 
http://doi.org/10.15359/ree.25-3.36

y superar sus propias dificultades. Todas estas actividades aportaron datos de cada individuo según el tiempo que emplearon en las diferentes lecturas y el tipo de dificultad según las dimensiones descritas en las variables medidas.

\section{Análisis de datos}

La correlación obtenida en datos cuantitativos se obtuvo del programa SPSS 20.0 (verTabla 4). La información de la variable del proceso de lectura aportó datos para realizar el proceso de correlación con la mediación cognitiva en las tres competencias descritas. Así mismo se realizó la prueba de Kolmogorov-Smirnov, y se detectó normalidad en los datos; por lo tanto, la prueba elegida fue el coeficiente de correlación de Pearson, el cual se define según Hernández Sampieri et al. (2014), como una prueba estadística para analizar la relación entre dos variables y determinar la fuerza que existe entre ellas. De acuerdo con esto, cuanto más cerca esté de cero el coeficiente obtenido, menor o más débil es la correlación entre las variables.

\section{Resultados}

Los datos procesados se dividen en dos aspectos fundamentales: por un lado, la descripción independiente de las dos variables analizadas: la del proceso de lectura apoyada en TIC y la variable de mediación cognitiva; a cada una se le analizó el resultado por dimensiones como se planteó en la metodología. El otro aspecto de relevancia es el resultado de la correlación de las dos variables: proceso de lectura apoyado en TIC con la mediación cognitiva.

\section{Análisis descriptivo de los resultados de la variable: Proceso de lectura apoyada por TIC}

Una vez desarrolladas las actividades de lectura apoyadas porTIC, se solicitó al estudiantado resolver el cuestionario con escala Likert y valorar su proceso individual.

Figura 1: Niveles de la dimensión silabeo / segmentación en el proceso de lectura

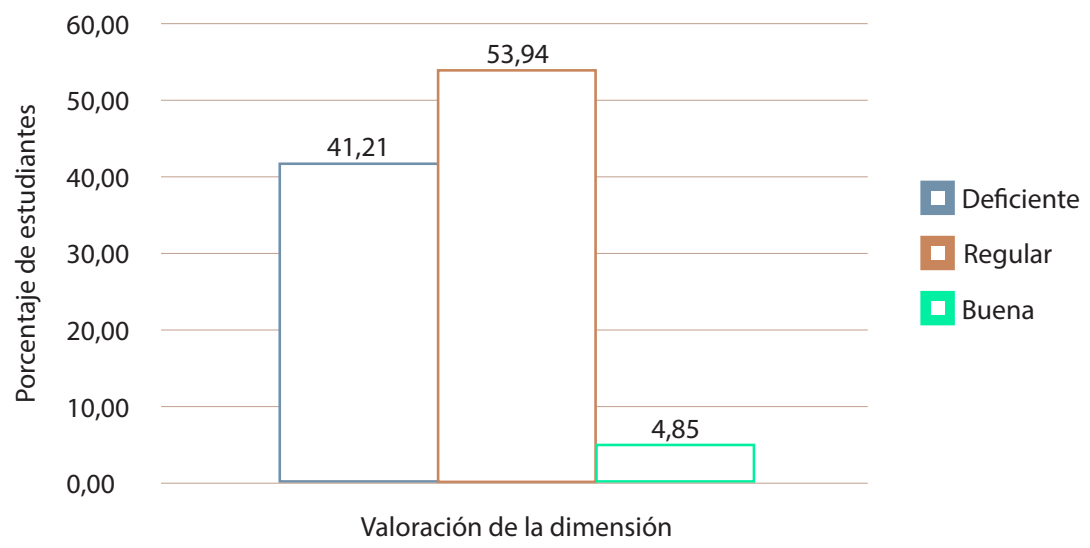

Nota: Elaboración propia. 
http://doi.org/10.15359/ree.25-3.36

http://www.una.ac.cr/educare

educare@una.ac.cr

El porcentaje de estudiantes que reconoce un proceso de lectura deficiente al segmentar las palabras es alto; el $42,21 \%$ tiene una lectura deficiente, una lectura que es lenta por la debilidad de estar pendiente de las sílabas en lugar de las palabras; aspectos analizados en Dehaene (2014) y Dehaene et al. (2015). Un número mayor de estudiantes, el 53,94\%, considera su proceso lector medianamente aceptable, o lo que indica la Figura 1, regular; una pequeña porción de la muestra está de acuerdo en llevar a cabo un proceso de lectura no segmentada, su forma de leer es óptima y les garantiza un mejor desempeño en su proceso académico como establecieron Timarán Pereira et al. (2020).

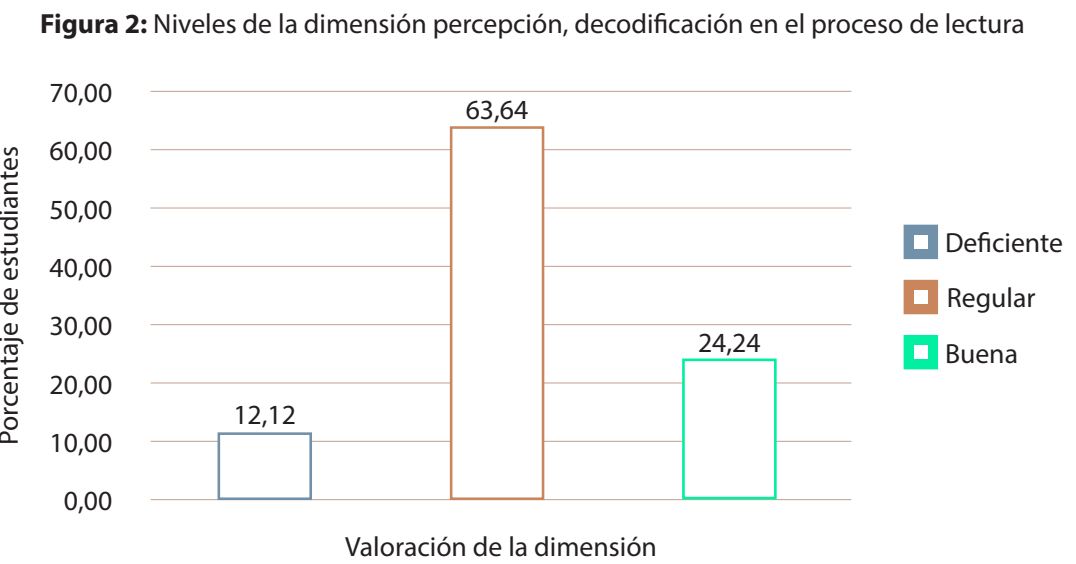

Nota: Elaboración propia.

El nivel regular para la percepción y decodificación durante la lectura es relevante, según muestra la Figura 2 y representa a la mayoría del estudiantado encuestado con un 63,64\%; en segundo lugar, una significativa parte de la muestra reconoce como buena su habilidad para percibir y decodificar palabras y expresiones en el proceso de lectura; y solo un 12,12\% acepta una deficiencia en este tipo de proceso lector. Este asunto lo documentó Vaca Uribe (2000) en dos aspectos: por un lado, una decodificación deficiente donde el sujeto lector debe fijarse en cada uno de los elementos que componen la palabra; y uno más avanzado en el que reconoce las palabras sin dificultad, porque ya las ha procesado su cerebro y las tiene almacenadas en la memoria.

De los distintos defectos de lectura analizados, los resultados expuestos en la Figura 3 muestran las deficiencias muy cercanas de una capacidad regular en este proceso lector. El $47,88 \%$ de los sujetos encuestados considera que tiene pronunciados defectos al leer; en el término medio, el $49,7 \%$ valora su actividad lectora como regular tratándose de incurrir en defectos de lectura; mientras que el $2,42 \%$ se destaca por una lectura libre de defectos. Esta situación coincide con planteamientos de Sánchez (1990) y Dehaene (2014): los defectos de lectura, como sustituir letras o palabras, omitirlas o saltear renglones mientras se lee son recurrentes en el proceso de lectura y hasta implican un grado de conciencia de estar incurriendo en ellos para reconocerlos como defectos. 
http://doi.org/10.15359/ree.25-3.36

http://www.una.ac.cr/educare educare@una.ac.cr

Figura 3: Niveles de la dimensión defectos al leer en el proceso de lectura

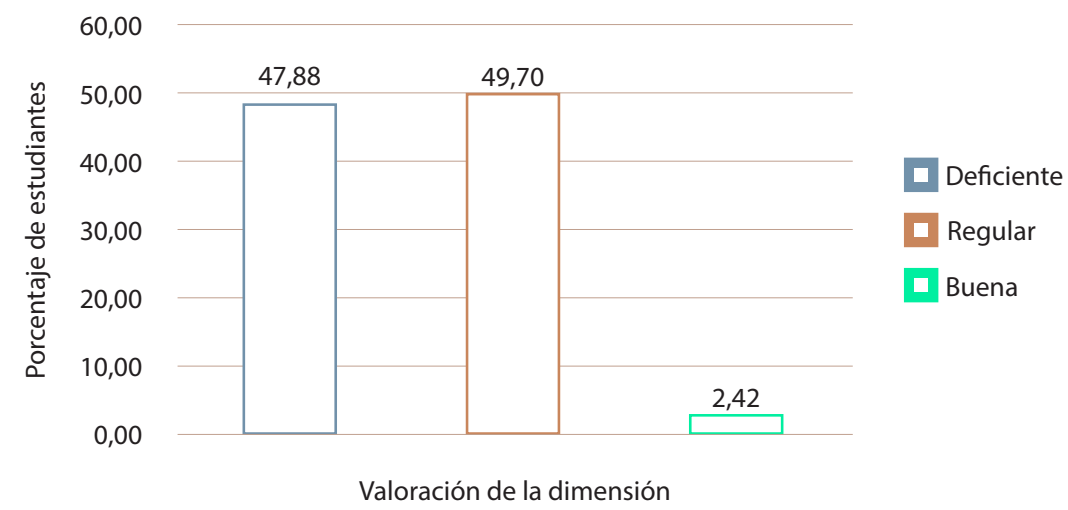

Nota: Elaboración propia.

\section{Análisis descriptivo de los resultados de la variable: Mediación cognitiva}

Figura 4: Niveles de la dimensión mediación a partir de la intencionalidad

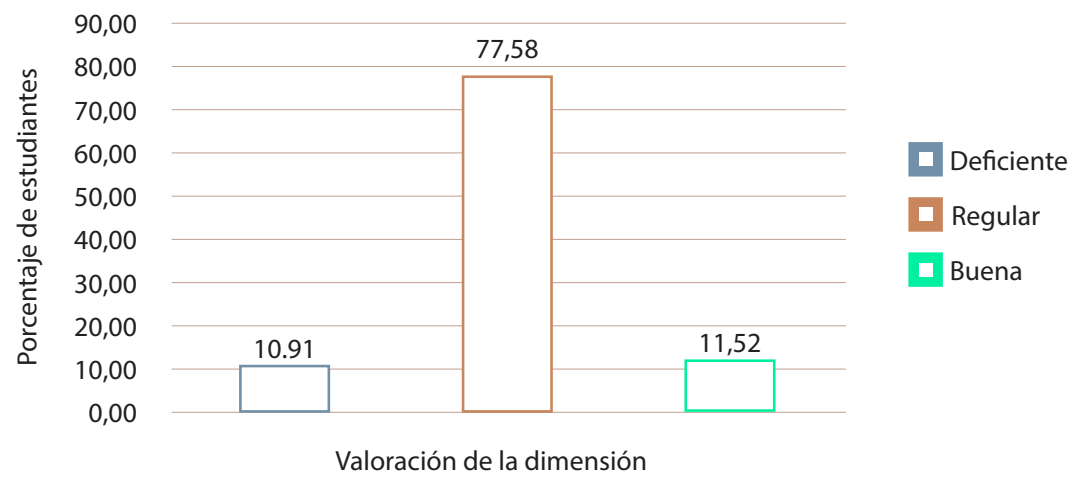

Nota: Elaboración propia.

La Figura 4, muestra que el 77,58\% de los sujetos encuestados aprecian como regular la mediación a partir de la intencionalidad en las actividades de lectura apoyadas por TIC que desarrollaron. La intencionalidad es pronunciada como buena en 11,52\% de los sujetos encuestados, y 10,91\% la consideran deficiente. Entender la intencionalidad de las actividades, el propósito de cada una de ellas es fundamental para el proceso de una lectura fluida. Guiñez Elorz y Martínez Palma (2015) y Tebar Belmonte (2009) identifican en la intencionalidad una dimensión de reciprocidad intrínseca en el estudiantado cuando asume un rol de mediador para su proceso de mediación cognitiva. En otras palabras, el texto le ofrece al sujeto lector una puerta abierta que al cruzarla implica interacción pasiva-activa; pasiva porque el texto no cambia y activa cuando es la persona que lee quien recibe el contenido del texto y lo procesa desde su cognición. 
http://doi.org/10.15359/ree.25-3.36

http://www.una.ac.cr/educare

educare@una.ac.cr

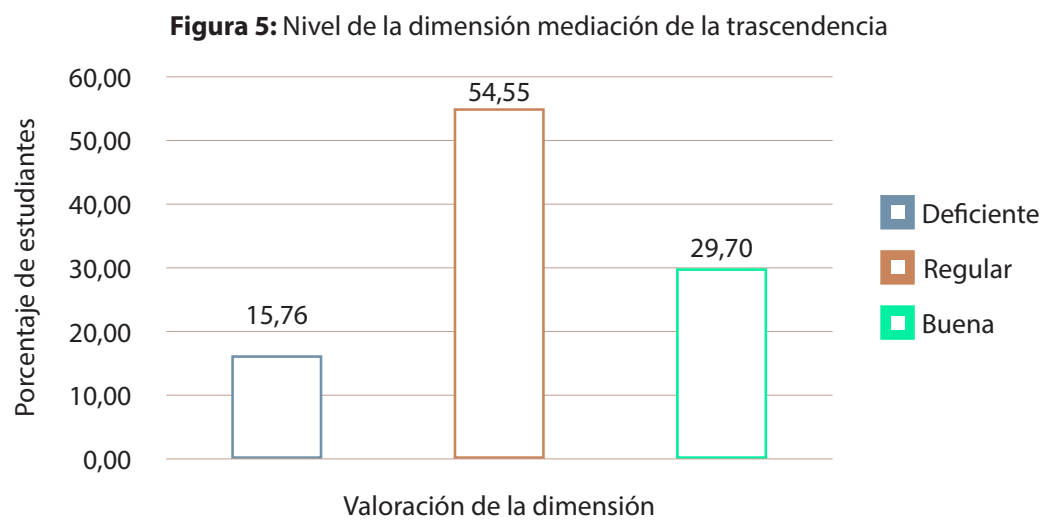

Nota: Elaboración propia.

Como se puede observar en la Figura 5, la trascendencia refleja una tendencia significativa, puesto que el $54,55 \%$ relaciona los saberes adquiridos en el aula a través de las actividades de lectura con otros contextos y un $29,7 \%$ ve, en esas actividades, escenarios de participación fuera del entorno escolar, una utilidad al aprendizaje a través de la lectura. En contraposición, un 15,76\% no visualiza ni pone en práctica el aprendizaje que adquiere a través de lecturas mediadas por TIC. El concepto de trascendencia se aborda desde la perspectiva de transferir la práctica de la lectura apoyada en TIC a un escenario distinto al contexto educativo. Gutiérrez (2009) invita:

[A] comprender la práctica lectora en el contexto de la convergencia digital, entendida como un cambio fundamental en la dinámica del ecosistema de comunicación en el que habitamos contemporáneamente, que, más allá de referirse a las tecnologías, describe la movilidad de los modos de hacer humanos, en el proceso de participar en las luchas cotidianas por el sentido y por suplir sus necesidades como habitantes de dicho ecosistema. (pp. 145-146)

Postura que representa un sentido de trascendencia para cuestionar los propósitos implícitos en el acto de leer. Gómez Martínez (2007) manifiesta en la trascendencia una utilidad en otro contexto dentro de las interacciones sociales a través del lenguaje y la construcción de experiencias individuales y colectivas con el mundo.

En este último resultado, el estudiantado determinó como regular el sentimiento de competencia en un 49,7\%; y muy cerca de este resultado, una calificación deficiente con 47,88\% estima que hace falta trabajar más en materializar las habilidades individuales, como se observa en la Figura 6. Aquí, se ha trabajado sobre el planteamiento de Gómez Martínez (2007) en donde la materialización del sentimiento de competencia está ligada a la sensación de éxito que experimenta el estudiantado al culminar sus actividades de lectura apoyadas en TIC que le llevan a reflexionar y constatar que se produjeron avances significativos en su habilidad para leer. 
Figura 6: Nivel de la dimensión del sentimiento de competencia

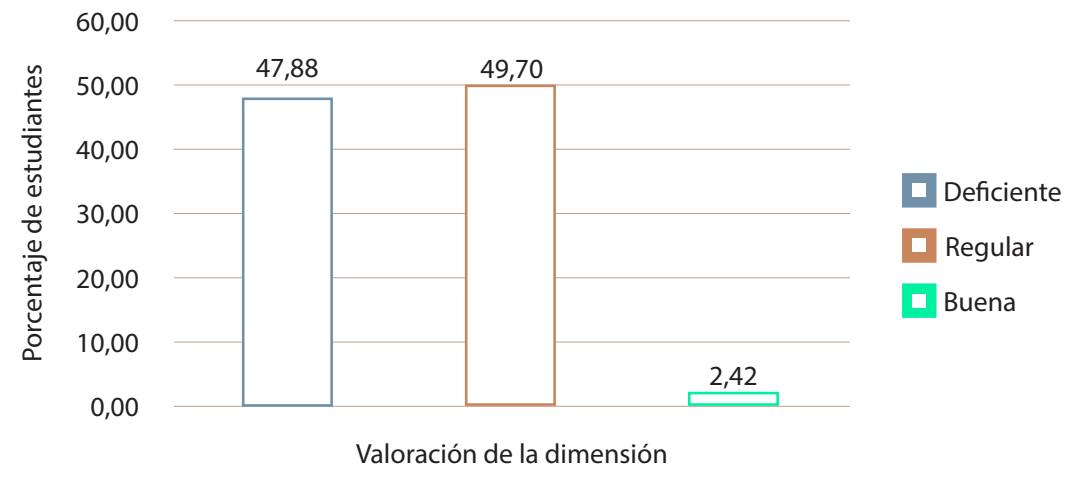

Nota: Elaboración propia.

\section{Prueba de normalidad}

Según la prueba de normalidad practicada en SPSS statistic (Tabla 3), con el Z de Kolmogorov y Smirnov, se halló una significancia de 0,424 para la variable 1, proceso de lectura y de 0,695 para la variable 2, mediación cognitiva, datos superiores a 0,05 por lo tanto, se optó por analizar datos con el coeficiente de correlación de Pearson para la prueba de hipótesis.

Tabla 3: Prueba normalidad: Kolmogorov-Smirnov

\begin{tabular}{|c|c|c|c|}
\hline & & $\mathrm{V}_{1}$ : Proceso de lectura & $V_{2}:$ Mediación cognitiva \\
\hline & & 165 & 165 \\
\hline \multirow{2}{*}{ Parámetros normales ${ }^{a, b}$} & Media & 57,93 & 61,47 \\
\hline & Desviación típica & 8,513 & 10,442 \\
\hline \multirow{3}{*}{ Máximas más extremas } & Absoluta & 0,068 & 0,055 \\
\hline & Positivo & 0,068 & 0,042 \\
\hline & Negativo & $-0,039$ & $-0,055$ \\
\hline Z de Kolmogorov & & 0,878 & 0,710 \\
\hline Sig. Asintónica (bilateral) & & 0,424 & 0,695 \\
\hline
\end{tabular}

a. La distribución de contraste es la normal

b. Se ha calculado a partir de los datos

Nota: Elaboración propia. 
http://doi.org/10.15359/ree.25-3.36

http://www.una.ac.cr/educare

educare@una.ac.cr

Según se observa (Tabla 4) no hay información suficiente para aceptar la hipótesis nula y teniendo en cuenta el nivel de significancia que no supera el 0,05 se acepta la hipótesis alterna; además, del resultado se interpreta como una moderada correlación $\left(r_{x y}=0.558\right.$, donde $\left.p>0.05\right)$, lo cual indica que el proceso de lectura apoyado en TIC está relacionado con la mediación cognitiva de estudiantes de grados décimo y undécimo de un colegio público.

Tabla 4: Correlación entre proceso de lectura y mediación cognitiva

\begin{tabular}{|c|c|c|c|c|}
\hline & & & $\mathrm{X}$ : Proceso de lectura & Y: Mediación cognitiva \\
\hline \multirow{6}{*}{$\begin{array}{l}\text { Coeficiente de } \\
\text { correlación de } \\
\text { Pearson }\end{array}$} & \multirow{3}{*}{$\mathrm{X}$ : Proceso de lectura } & Correlación de Pearson & 1 & $0,558^{* *}$ \\
\hline & & Sig. (bilateral) & . & 0,000 \\
\hline & & $\mathrm{N}$ & 165 & 165 \\
\hline & \multirow{3}{*}{ Y: Mediación cognitiva } & Correlación de Pearson & $0,558^{* *}$ & 1 \\
\hline & & Sig. (bilateral) & 0,000 & . \\
\hline & & $\mathrm{N}$ & 165 & 165 \\
\hline
\end{tabular}

** La correlación es significativa al nivel 0,01 (bilateral).

Nota: Elaboración propia.

La correlación positiva entre el proceso de lectura apoyado en TIC y la mediación cognitiva permite sugerir una relación adicional que resalta la fluidez dentro del proceso descrito. Esta suposición empírica se establece a partir de la misma correlación establecida; si se tiene en cuenta que la mediación cognitiva del estudiantado aporta a su desarrollo intelectual; asimismo la fluidez lectora es pieza fundamental que incide en esa mediación cognitiva y prueba de ello se sustenta en los estudios de Dehaene et al. (2015) y Sánchez (1990); y en esta relación, los ejercicios de lectura con apoyo de las TIC implementados en el estudiantado contribuyen con aumentar su capacidad de fluidez y su mediación cognitiva.

Prueba de hipótesis. Sobre la hipótesis general, los resultados del análisis estadístico en SPSS indican que existe poca información para aceptar la hipótesis nula y teniendo en cuenta el nivel de significancia que no supera el 0,05 se acepta la hipótesis alterna; además, del resultado, se interpreta como una moderada correlación $\left(r_{x y}=0.558\right.$, donde $\left.p>0.05\right)$, lo que indica que el proceso de lectura está relacionado con la mediación cognitiva.

En relación con las hipótesis específicas: En la primera, se estima moderada relación $\left(r_{x y}=0,505\right.$, donde $\left.p<0,05\right)$ entre el proceso de lectura y la mediación de intencionalidad. Adicionalmente, la significancia bilateral de 0,000 se halla bajo el valor permitido y da razón 
http://doi.org/10.15359/ree.25-3.36

para afirmar que es aceptada la hipótesis alterna, puesto que existe relación significativa entre el proceso de lectura con apoyo de TIC y la dimensión intencionalidad de la mediación cognitiva. En la segunda, los resultados de la correlación entre la variable proceso de lectura y la dimensión de trascendencia de la mediación cognitiva se considera moderada de acuerdo con la interpretación de Pearson, teniendo en cuenta que $\left(r_{x y}=0,495\right.$, donde $\left.p<0,05\right)$. Dada la significancia bilateral de 0,000 ajustada al valor permitido, se puede establecer la correlación planteada en la hipótesis específica alterna, en el sentido siguiente: Existe relación significativa entre el proceso de lectura con apoyo de TIC y la dimensión trascendencia de la mediación cognitiva y en la tercera, los resultados dan a interpretar una escasa relación $\left(r_{x y}=0,385\right.$, donde $p<0,05)$ entre el proceso de lectura y el sentimiento de competencia de la mediación cognitiva del estudiantado encuestado. La significancia obtenida es de 0,000 y se ajusta a los límites permitidos, por lo tanto, se acepta la hipótesis específica alterna que indica la existencia de una relación significativa entre el proceso de lectura con apoyo de TIC y la dimensión sentimiento de competencia de la mediación cognitiva.

\section{Conclusiones}

- Existe una relación significativa al nivel 0,01 (bilateral); el coeficiente de correlación es $r=0,505$ y un $p$-valor $=0,00(p<0,05)$. De lo cual se puede concluir que el estudiantado lee de las actividades que se diseñaron mediados por TIC, e identifican un para qué, lo relacionan con procesos cognitivos, encuentran un propósito a la actividad, aunque se presenten algunas dificultades de fluidez en el proceso. No obstante, del proceso de leer con fluidez, los resultados que se describieron indicaron que son pocos individuos quienes lo logran, y un porcentaje bajo reconoce buenos resultados en su proceso lector y su mediación cognitiva.

- La relación que existe entre el proceso de lectura con apoyo de TIC y la dimensión trascendencia de la mediación cognitiva es significativa al nivel 0,01 (bilateral); el coeficiente de correlación es $r=0,495$ y un $p$-valor $=0,00(p<0,05)$. De lo cual se puede concluir que el estudiantado en este sentido se muestra un poco más disperso, puesto a una gran mayoría se le dificulta hallar la relación de los procesos lectores con la aplicación de sus aprendizajes mediados por las TIC en asuntos lectores con la aplicación de ellos en otros contextos.

- Los resultados indican una relación significativa entre el proceso de lectura con apoyo de TIC y la dimensión sentimiento de competencia de la mediación cognitiva al nivel 0,01 (bilateral); el coeficiente de correlación es $r=0,385$ y un $p$-valor $=0,00(p<0,05)$. Sin embargo, la dimensión de sentimiento de competencia de la mediación cognitiva está más distante de los resultados obtenidos en las otras correlaciones anteriores. Para el estudiantado, la visión de liderar procesos o de sentirse rechazado o aceptado 
http://doi.org/10.15359/ree.25-3.36

http://www.una.ac.cr/educare

educare@una.ac.cr

por sus resultados como sujetos lectores no representa mucho interés, si se analizan detalladamente los resultados en la estadística descriptiva. Ahora bien, esto no quiere decir que los datos estén tan separados entre ellos; sino que se explican a partir del contexto socioeconómico en el que el estudiantado ha sido formado.

- Existe un grado de correlación moderada entre el proceso de lectura con apoyo de las TIC y la mediación cognitiva de estudiantes de media del Colegio Jorge Eliécer Gaitán de Aguazul-Colombia 2018 ( $r=0,558$ y un $p$-valor =0,00). La lectura en sí misma es un proceso cognitivo que requiere de habilidades que el estudiantado va incorporando a medida que transcurre su tránsito por la escuela. Pero, no se desarrolla de igual manera en todos los sujetos, unos aprenden más y mejor que otros, el interés que alguno demuestra por las actividades que se desarrollan, más la motivación que reciben de sus docentes, de sus familias y del contexto social en el que se desenvuelven son variables de peso que no se estudiaron en esta investigación y que valdría la pena revisar en futuros proyectos.

- Las prácticas de lectura apoyadas en TIC ayudaron a desarrollar fluidez en estudiantes que presentaban dificultad; esta relación a su vez propicia la mediación cognitiva del estudiantado. Los datos expuestos a nivel de correlación aportan evidencia para soportar esta afirmación. Estudios como el de Amórtegui Luna (2017) contribuyen también a ampliar la idea de que la fluidez lectora se asocia con el desarrollo de la mediación cognitiva del estudiantado. Sobre la fluidez, de Zubiría Samper (1996) considera que está determinada por la claridad del contenido del texto en un proceso que denomina cromatización inscrito en la decodificación secundaria y a medida que el texto se hace complejo, el aspecto de fluidez puede verse afectado; no obstante, en esta investigación no se acercó con instrumentos suficientes para analizar esta perspectiva y valdría la pena hacerlo en investigaciones futuras.

\section{Declaración de Material complementario}

Este artículo tiene disponible, como material complementario:

-La versión preprint del artículo en https://doi.org/10.5281/zenodo.4414881

\section{Referencias}

Amórtegui Luna, L. F. (2017). Mediación y lectura en voz alta: Estrategias para la oralidad [Tesis de licenciatura].UniversidadPedagógicaNacionaldeColombia.http://repositorio.pedagogica. edu.co/bitstream/handle/20.500.12209/3254/TE-21140.pdf?sequence=1\&isAllowed=y 
http://doi.org/10.15359/ree.25-3.36

Cañadas Osinski, I. y Sánchez Bruno, A. (1998). Categorías de respuesta en escalas tipo Likert. Psicothema, 10(3), 623-631. http://www.psicothema.com/psicothema.asp?id=191

Carmona García, V. E. y Martínez Gutiérrez, I. A. (2012). Las TIC como estrategia para mejorar la lectura comprensiva en los estudiantes de $6^{\circ}$ de la institución educativa María Inmaculada [Tesis de licenciatura]. Universidad de Cartagena. https://repositorio.unicartagena. edu.co/bitstream/handle/11227/235/PROYECTO\%20IRINA\%20MARTINEZ\%20Y\%20 VLADIMIR\%20CARMONA.pdf?sequence=1\&isAllowed=y

de Zubiría Samper, M. (1996). Teoría de las seis lecturas: Cómo enseñar a leer y a escribir ensayos. Fundación Alberto Merani.

Dehaene, S. (2014). El cerebro lector: Últimas noticias de las neurociencias sobre la lectura, la enseñanza, el aprendizaje y la dislexia (M. J. D’Alessio, Trad.) Siglo Veintiuno Editores.

Dehaene, S., Cohen, L., Morais, J. y Kolinsky, R. (2015). Analfabetos a alfabetizados: Cambios conductuales y cerebrales inducidos por la adquisición de la lectura. Nature Reviews Neurociencia, 16, 234-244.

Feuerstein, R. y Rand, Y. (1974). Mediated learning experiences: An outline of the proximal etiology for differential development of cognitive functions. En L. G. Fein (Ed.), International Understanding-Cultural differences in the development of cognitive processes (pp. 7-37). International Council of Psychologists.

Feuerstein, R., Klein, P. S. y Tannenbaum, A. J. (Eds.). (1991), Mediated learning experience (MLE). Theoretical, psychosocial, and learning implications. Freund Publishing House. https:// books.google.com.co/books?id=NkSTx5oUfagC\&printsec=frontcover\&hl=es\&source=g bs ge summary $r \& c a d=0 \# v=$ onepage $\& q \& f=$ false

Filinich, M. I. (2003). Descripción. Eudeba.

Fraca de Barrera, L. (1998). La conciencia fonológica silábica y el aprendizaje de la lengua escrita, Venezuela. Lectura y Vida. Revista Latinoamericana de Lectura, 20(4), 1-8. http://www. lecturayvida.fahce.unlp.edu.ar/numeros/a20n4/20 04 Fraca.pdf

Fuentes Paipilla, S. C. y Ramírez Sánchez, P. A. (2017). Propuesta didáctica de mediación en la lectura literaria: "Una mirada de mi realidad" [Tesis de maestría]. Universidad de Santo Tomás. https://repository.usta.edu.co/bitstream/handle/11634/9241/FuentesSonia2017. pdf? sequence $=1$ \&isAllowed $=y$

Fumagalli, J.-C., Barreryo, J.-P- y Jaichenco, V.-I. (2017) Fluidez lectora en niños: Cuáles son las habilidades subyacentes. OCNOS Revista de estudios en lectura, 16(1), 50-61. https://doi. org/10.18239/ocnos 2017.16.1.1332 
http://doi.org/10.15359/ree.25-3.36

http://www.una.ac.cr/educare

educare@una.ac.cr

Funes, M. (1995). Prevención y A.C.I.s en las dificultades de lectura. Un enfoque psicolingüístico-cognitivo. Comunicación, Lenguaje y Educación, 7(4), 49-62. https://doi. org/10.1174/021470395763771855

Gómez Martínez, M. T. (2007). Mediación para la comprensión lectora en escuelas rurales de San Gil, Santander, Colombia. Revista Docencia Universitaria, 8, 189-205. Fonte: https://core. ac.uk/download/pdf/230236721.pdf

Guenaga, M. L., Barbier, A. y Eguiluz, A. (2007). La accesibilidad y las tecnologías en la información y la comunicación. TRANS. Revista de traductología, (11), 155-169. https://doi.org/10.24310/ TRANS.2007.v0i11.3104

Guiñez Elorz, M. y Martínez Palma, E. (2015). Mediación lectora y primera infancia: Construcción de sentidos subjetivos e identitarios. Estudio de caso en niños de $3^{\circ}$ y $4^{\circ}$ de educación básica del Colegio Adventista de Valdivia. Estudios Pedagógicos, 41(Especial), 115-134. https://doi.org/10.4067/S0718-07052015000300008

Gutiérrez, E. (2009). Leer digital: La lectura en el entorno de las nuevas tecnologías de la información y la comunicación. Signo y Pensamiento, 28(54), 144-163. https://www.redalyc. org/pdf/860/86011409010.pdf

Gutiérrez, R. (2018). Habilidades favorecedoras del aprendizaje de la lectura en alumnos de 5 y 6 años. Revista Signos, Estudios de Lingüística, 51(96) 45-60. https://doi.org/10.4067/S071809342018000100045

Hernández Sampieri, R., Fernández Collado, C. y Baptista Lucio, P. (2014). Metodología de la investigación (6..$^{\circ}$ ed.). McGraw Hill.

Hurtado, M. D. (2010). Las TIC como recurso en el acceso a la lecto-escritura. Centro de Recursos del CPEE.

Inciarte Romero, N. y Inciarte González, A. (2014). Mediación cognitiva como parte de los procesos de investigación. Encuentro Educacional, 21(2), 256-270. http://bit.ly/2OmNgDU

Luján Villar, J. D. (2015). Tecnologías cognitivas: Lectura y escritura. Revista Internacional Magisterio, (72), 24-28 https://www.researchgate.net/publication/318940156 Tecnologias_cognitivas_lectura_y_escritura

Núñez París, F. (2010). El papel del profesor como agente de mediación cognitiva. Aplicaciones prácticas de la investigación-acción y de las reflexiones, en el aula de francés como lengua extranjera. CiDd: Il Congrés Internacional de Didàctiques 2010 (pp. 1-8). Universitat de Girona. 
Paredes Labra, J. (2005). Animación a la lectura y TIC: Creando situaciones y espacios. Revista de Educación, (Extraordinario), 255-279. http://www.educacionyfp.gob.es/revista-deeducacion/numeros-revista-educacion/numeros-anteriores/2005/re2005/re2005-17.html

Parret, H. (1995). De la semiótica a la estética: Enunciación, sensación, pasiones. Edicial.

Piaget, J. (1985). Psicología y epistemología. Planeta-Agostini. https://riofa.files.wordpress. com/2011/03/psicologia-y-epistemologia-piaget.pdf

Pilonieta, G. (2010). Modificabilidad estructural cognitiva y educación. Magisterio Editorial.

Rasinski, T. (2004). Creating fluent readers. Educational Leadership, 61(6), 46-51. http://www.ascd.org/ publications/educational-leadership/mar04/vol61/num06/Creating-Fluent-Readers.aspx

Sánchez, E. (1990). Estrategias de intervención en los problemas de lectura. En A. Marchesi, C. Coll y J. Palacios (Eds.), Desarrollo psicológico y educación, III. Necesidades educativas especiales y aprendizaje escolar (Cap. 8, pp. 139-153) Alianza.

Siemens, G. (2004). Conectivismo: Una teoría de aprendizaje para la era digital. En R. Aparici (Coord.), Conectados con el ciberespacio (pp. 77-90). UNED.

Silva Manrique, Y. A., Serrano Alvarado, F. E. y Medina Peña, N. A. (2019). La lectura crítica mediada por las TIC en el contexto educativo. Educación y Ciencia, (22), 263-277. https://revistas. uptc.edu.co/index.php/educacion_y_ciencia/article/view/10051/8328

Tabash Blanco, N. (2010). La lectura interactiva en el desarrollo de las habilidades de comprensión de lectura y de expresión escrita. Revista de Lenguas Modernas, (12), 211-239. https:// revistas.ucr.ac.cr/index.php/rlm/article/download/9479/8929/

Tébar Belmonte, L. (2009). El profesor mediador del aprendizaje. Magisterio Editorial.

Timarán Pereira, R., Hidalgo Troya, A. y Caicedo Zambrano, J. (2020). Factores asociados al desempeño académico en Lectura Crítica en las pruebas Saber $11^{\circ}$ con árboles de decisión. 3 x IN Investigación e Innovación en Ingenierías, 8(3), 29-37. https://doi.org/10.17081/ invinno.8.3.4701

Vaca Uribe, J. E. (2000). Jérôme no lee como debe... según las teorías contemporáneas de la lectura. Lectura y Vida. Revista Latinoamericana de Lectura, 21(4), 1-20. http://www. lecturayvida.fahce.unlp.edu.ar/numeros/a21n4/21 04 Vaca.pdf/at download/file

Vygotsky, L. S. (1978). Interaction between learning and development. En M. Cole, V. John-Steiner, S. Scribner y E. Souberman (Eds.), Mind in society. The development of higher psychological processes (pp. 79-91). Harvard University Press. 
Apéndice A: Instrumento de recolección de información validado

\section{Cuestionario para medir la relacion entre el proceso de lectura y la mediación cognitiva}

Estimado/a alumno/a en el presente instrumento del trabajo de investigación le pedimos que sea sincero/a en sus respuestas, respondiendo los Ítems, ya que la información es de carácter confidencial y de uso exclusivo para la investigación.

Instrucciones: A continuación, se le presenta un conjunto de preguntas con sus posibles respuestas. Por favor responda marcando con una (X) la escala que crea conveniente

\begin{tabular}{|c|c|c|c|}
\hline Siempre & Casi siempre & A veces & Nunca \\
\hline 4 & 3 & 2 & 1 \\
\hline
\end{tabular}

\begin{tabular}{|c|c|c|c|c|c|}
\hline \multicolumn{6}{|c|}{ VARIABLE 1: PROCESO DE LECTURA } \\
\hline & DIMENSIÓN: SEGMENTACIÓN SILABEO & 4 & 3 & 2 & 1 \\
\hline \multicolumn{6}{|c|}{ Lectura de palabras } \\
\hline 1 & Al leer una palabra común y sencilla como "venerar" visualiza las sílabas que la contienen "VE - NE - RAR". & & & & \\
\hline 2 & Al leer una palabra de poco uso y compleja como"pusilánime" visualiza las sílabas que la contienen “PU - SI - LÁ - NI - ME". & & & & \\
\hline 3 & $\begin{array}{l}\text { Al leer una palabra desconocida como "borborigmo", se detiene para descomponer sus sílabas y pensar en su } \\
\text { posible significado. }\end{array}$ & & & & \\
\hline \multicolumn{6}{|c|}{ Léxico } \\
\hline 4 & Al leer un texto, halla palabras de difícil pronunciación que detienen su lectura. & & & & \\
\hline 5 & Cuando encuentra palabras desconocidas, las vuelve a leer. & & & & \\
\hline 6 & Consulta el significado de palabras dudosas o de difícil pronunciación. & & & & \\
\hline & DIMENSIÓN: PERCEPCIÓN DECODIFICACIÓN & 4 & 3 & 2 & 1 \\
\hline \multicolumn{6}{|c|}{ Extensión del texto } \\
\hline 7 & Identifica el final de una frase y el comienzo de otra, realizando el cambio respectivo. & & & & \\
\hline 8 & Realiza pausas según los signos de puntuación de la lectura. & & & & \\
\hline 9 & La pausa coincide con la entonación final que requiere la lectura de signos de interrogación o de exclamación. & & & & \\
\hline \multicolumn{6}{|c|}{ Pronominalización } \\
\hline 10 & Identifica el sujeto de quien se habla o a quien se refiere el texto. & & & & \\
\hline 11 & Comprende otras formas de referirse dentro del texto al sujeto (uso de pronombres como "este, él, aquel"). & & & & \\
\hline \multicolumn{5}{|c|}{ Relativización } & \\
\hline 12 & Las expresiones afirmativas del texto son más fáciles de leer. & & & & \\
\hline 13 & Cuando el texto le ofrece expresiones negativas, analiza con más cuidado lo que le quiere decir. & & & & \\
\hline 14 & La lectura de frases negativas le exigen analizar el contenido del texto. & & & & \\
\hline
\end{tabular}

continúa 


\begin{tabular}{|c|c|c|c|c|c|}
\hline & DIMENSIÓN: DEFECTOS AL LEER & 4 & 3 & 2 & 1 \\
\hline \multicolumn{6}{|c|}{ Omisión de letras o palabras } \\
\hline 15 & La lectura de una frase que inició en plural la termina leyendo en singular. & & & & \\
\hline 16 & El sentido del texto no fue comprendido por no leer una palabra clave. & & & & \\
\hline 17 & Relee un párrafo, porque saltó un renglón completo perdiendo la noción de lo que estaba leyendo. & & & & \\
\hline 18 & En una lectura, una palabra como "colmo" puede leer "como" omitiendo la 'I'. & & & & \\
\hline 19 & $\begin{array}{l}\text { En una lectura, una expresión que dice "La variedad de situaciones de escritura requieren de distintos tipos de } \\
\text { lectura", puede llegar a leer "La variedad de situaciones requieren distintos tipos de lectura" omitiendo'de escritura'. }\end{array}$ & & & & \\
\hline \multicolumn{6}{|c|}{ Adición de letras o palabras } \\
\hline 20 & Al leer un texto la palabra "efecto" puede leer "efectúo" adicionando la 'u'. & & & & \\
\hline 21 & $\begin{array}{l}\text { Al leer una expresión que dice "Los estudiantes leen sin atender al sentido de la lectura" puede llegar a leer "Los } \\
\text { estudiantes no leen sin atender al sentido de la lectura" adicionando la palabra 'no'. }\end{array}$ & & & & \\
\hline \multicolumn{6}{|c|}{ Sustitución de letras o palabras } \\
\hline 22 & Al leer una palabra como "excepción" puede llegar a leer "ascensión" sustituyendo las letras 'ex__pc'. & & & & \\
\hline 23 & $\begin{array}{l}\text { Al leer una expresión como "El arte de leer fluido es también la clave para triunfar" lee algo como "El arte de leer } \\
\text { fluido es también la llave para triunfar" sustituyendo la palabra 'clave' por 'llave'. }\end{array}$ & & & & \\
\hline \multicolumn{6}{|c|}{ Relectura } \\
\hline 24 & Una palabra como "sempiterno" la lee otra vez porque cree que leyó algo que no era. & & & & \\
\hline 25 & $\begin{array}{l}\text { El fragmento de un texto como "La escasa injerencia del docente en aquellos hábitos negativos del estudiante } \\
\text { limitan su acceso al aprendizaje" le incitan a releer para comprender mejor lo que dice. }\end{array}$ & & & & \\
\hline \multicolumn{6}{|c|}{ VARIABLE 2: MEDIACIÓN COGNITIVA } \\
\hline & DIMENSIÓN: MEDIACIÓN A PARTIR DE LA INTENCIONALIDAD & 4 & 3 & 2 & 1 \\
\hline \multicolumn{6}{|c|}{ Propósito de la actividad } \\
\hline 26 & Su velocidad lectora se fortalece practicando las lecturas. & & & & \\
\hline 27 & Siente rechazo hacia los ejercicios de lectura. & & & & \\
\hline 28 & Desarrolla los ejercicios de lectura por cumplir el horario de la asignatura. & & & & \\
\hline \multicolumn{6}{|c|}{ Operaciones mentales y funciones cognitivas } \\
\hline 29 & Al realizar los ejercicios de lectura, logra identificar planteamientos del autor/a. & & & & \\
\hline 30 & Al leer, compara el contenido con otros textos que ya leyó. & & & & \\
\hline 31 & Al terminar de leer un texto, logra sintetizar la información. & & & & \\
\hline \multicolumn{6}{|c|}{ Propósito en la implementación de estrategias de lectura } \\
\hline 32 & Mientras lee se concentra. & & & & \\
\hline 33 & Al leer le es posible analizar la información. & & & & \\
\hline 34 & Cuando lee procura finalizar rápido el ejercicio. & & & & \\
\hline
\end{tabular}


http://doi.org/10.15359/ree.25-3.36

http://www.una.ac.cr/educare

educare@una.ac.cr

\section{Percepción de estímulos del entorno}

35 Su nivel de concentración disminuye por efectos del ruido.

36 La temperatura o la iluminación interfiere en el ánimo para la realización de los ejercicios de lectura.

37 Cuando desarrolla los ejercicios de lectura suele pensar en problemas o preocupaciones particulares.

\section{DIMENSIÓN: MEDIACIÓN DE LA TRASCENDENCIA}

Aplicabilidad del aprendizaje en otros contextos

\begin{tabular}{|l|l}
\hline 38 & Las estrategias de lectura que emplea, las utiliza en otros escenarios distintos al escolar. \\
\hline 39 & El contenido de los textos le sirve para amenizar conversaciones familiares, sociales u otros contextos.
\end{tabular}

\section{Detalles del proceso de aprendizaje}

40 La atención que le dedica a las actividades de lectura influye en su proceso de aprendizaje.

41 Su aprendizaje se ve influenciado por el tiempo que dedica a cada actividad propuesta.

42 La fluidez y su capacidad de entendimiento de las lecturas aporta a su proceso de aprendizaje.

DIMENSIÓN: MEDIACIÓN DEL SENTIMIENTO DE COMPETENCIA

Deprivación cultural

43 Si obtiene resultados satisfactorios en las actividades de lectura, sus compañeros/as se sienten orgullosos y/o felices.

44 Es objeto de burlas, críticas o rechazo de parte de sus compañeros por su desempeño en las actividades de lectura.

45 Presiente que algunos/as compañeros/as hablan a sus espaldas de su desempeño en las actividades de lectura.

\section{Logros pequeños, inmediatos y crecientes}

\begin{tabular}{|l|l|l|l|l|}
\hline 46 & Al desarrollar las actividades de lectura, mejora su capacidad de comprensión de ejercicios en otras áreas académicas. & & & \\
\hline 47 & Encuentra relación entre la actividad lectora y la actividad física o de deportes. & & & \\
\hline
\end{tabular}

Trabajo colaborativo, autonomía y liderazgo

48 Demuestra interés en ayudar a otros a mejorar su desempeño en actividades de lectura.

49 Promovería un concurso de lectura en su salón.

50 Comenta a sus compañeros/as sobre el contenido de libros que está leyendo o ha terminado de leer. 
http://doi.org/10.15359/ree.25-3.36

http://www.una.ac.cr/educare educare@una.ac.cr

Apéndice B: Confiabilidad

\begin{tabular}{|c|c|}
\hline Alfa de Cronbach & N de elementos \\
\hline, 837 & 54 \\
\hline
\end{tabular}

\begin{tabular}{|c|c|c|c|c|}
\hline & $\begin{array}{l}\text { Media de la escala si se } \\
\text { elimina el elemento }\end{array}$ & $\begin{array}{l}\text { Varianza de la escala si se } \\
\text { elimina el elemento }\end{array}$ & $\begin{array}{c}\text { Correlación elemento-total } \\
\text { corregida }\end{array}$ & $\begin{array}{l}\text { Alfa de Cronbach si se elimina } \\
\text { el elemento }\end{array}$ \\
\hline Ítem 1 & 135,40 & 227,378 & 106 & 838 \\
\hline Ítem 2 & 135,70 & 204,900 & ,739 & ,821 \\
\hline Ítem 3 & 134,90 & 215,656 & ,412 & ,831 \\
\hline Ítem 4 & 134,60 & 212,267 & 692 & ,825 \\
\hline Ítem 5 & 134,40 & 216,711 & ,468 & ,830 \\
\hline Ítem 6 & 135,70 & 218,900 & ,575 & 830 \\
\hline Ítem 7 & 134,10 & 234,989 &,- 289 & 842 \\
\hline Ítem 8 & 134,50 & 219,833 & 319 & ,833 \\
\hline Ítem 9 & 134,80 & 211,956 & 704 & ,825 \\
\hline Ítem 10 & 134,90 & 205,656 & ,917 & 819 \\
\hline Ítem 11 & 135,00 & 210,444 & 702 & 824 \\
\hline Ítem 12 & 136,00 & 219,333 & ,545 & 830 \\
\hline Ítem 13 & 136,10 & 214,322 & ,775 & ,826 \\
\hline Ítem 14 & 135,60 & 226,489 & ,226 & ,835 \\
\hline Ítem 15 & 136,10 & 234,767 &,- 214 & 843 \\
\hline Ítem 16 & 135,90 & 224,100 & 252 & ,835 \\
\hline Ítem 17 & 134,70 & 203,122 & 797 & ,819 \\
\hline Ítem 18 & 136,40 & 230,933 &,- 035 & 840 \\
\hline Ítem 19 & 136,10 & 236,322 &,- 285 & 844 \\
\hline Ítem 20 & 135,80 & 251,289 &,- 581 & ,858 \\
\hline Ítem 21 & 135,40 & 249,378 &,- 485 & ,858 \\
\hline Ítem 22 & 136,40 & 229,378 & 041 & ,838 \\
\hline Ítem 23 & 135,90 & 212,100 & ,582 & ,827 \\
\hline Ítem 24 & 134,30 & 229,344 & ,040 & ,838 \\
\hline Ítem 25 & 134,50 & 222,944 & 251 & ,835 \\
\hline
\end{tabular}

continúa 
http://doi.org/10.15359/ree.25-3.36

http://www.una.ac.cr/educare

educare@una.ac.cr

\begin{tabular}{|c|c|c|c|c|}
\hline & $\begin{array}{l}\text { Media de la escala si se } \\
\text { elimina el elemento }\end{array}$ & $\begin{array}{l}\text { Varianza de la escala si se } \\
\text { elimina el elemento }\end{array}$ & $\begin{array}{c}\text { Correlación elemento-total } \\
\text { corregida }\end{array}$ & $\begin{array}{l}\text { Alfa de Cronbach si se elimina } \\
\text { el elemento }\end{array}$ \\
\hline Ítem 26 & 134,30 & 216,900 & ,526 & 829 \\
\hline Ítem 27 & 134,10 & 228,100 & ,148 & ,836 \\
\hline Ítem 28 & 136,00 & 237,111 &,- 448 & ,843 \\
\hline Ítem 29 & 134,70 & 237,344 &,- 346 & 844 \\
\hline Ítem 30 & 134,90 & 216,767 & ,572 & 829 \\
\hline Ítem 31 & 135,20 & 226,400 & 178 & ,836 \\
\hline Ítem 32 & 134,80 & 219,733 & 631 & 830 \\
\hline Ítem 33 & 134,50 & 231,611 &,- 069 & 840 \\
\hline Ítem 34 & 134,60 & 226,267 & 239 & ,835 \\
\hline Ítem 35 & 134,70 & 216,011 & ,437 & 830 \\
\hline Ítem 36 & 135,40 & 208,933 & 673 & 824 \\
\hline Ítem 37 & 134,30 & 235,122 &,- 230 & ,843 \\
\hline Ítem 38 & 134,70 & 220,011 & ,350 & ,833 \\
\hline Ítem 39 & 134,80 & 212,400 & ,532 & ,827 \\
\hline Ítem 40 & 135,60 & 219,378 & ,253 & ,836 \\
\hline Ítem 41 & 134,80 & 231,067 &,- 048 & ,843 \\
\hline Ítem 42 & 134,70 & 230,456 & ,000 & ,838 \\
\hline Ítem 43 & 134,50 & 219,611 & ,447 & ,831 \\
\hline Ítem 44 & 134,70 & 212,900 & ,718 & ,825 \\
\hline Ítem 45 & 134,60 & 215,822 & ,548 & ,828 \\
\hline Ítem 46 & 134,00 & 220,222 & ,499 & 831 \\
\hline Ítem 47 & 135,60 & 222,044 & ,301 & 834 \\
\hline Ítem 48 & 136,30 & 232,900 &,- 114 & 842 \\
\hline Ítem 49 & 136,40 & 230,933 &,- 035 & 840 \\
\hline Ítem 50 & 134,40 & 216,489 & ,558 & ,829 \\
\hline Ítem 51 & 135,50 & 232,722 &,- 096 & ,845 \\
\hline Ítem 52 & 135,40 & 224,267 & 233 & ,835 \\
\hline Ítem 53 & 135,90 & 218,322 & 370 & ,832 \\
\hline Ítem 54 & 135,50 & 214,056 & ,462 & ,829 \\
\hline
\end{tabular}

\footnotetext{
26 Alba Luz Arenas-Parada, Libardo Roa-Muños, Jairo Abelardo Centeno-Villamizary Kenier Iván Téllez López 